\title{
EL LENGUAJE JURÍDICO EN DOCUMENTOS DE LA COLECCIÓN DIPLOMÁTICA DE CALAHORRA
}

\author{
Aurora Martínez Ezquerro* \\ Universidad de La Rioja
}

\begin{abstract}
RESUMEN: En el presente artículo se muestran, desde la perspectiva lingüística, algunos de los rasgos que caracterizan la prosa notarial de la Edad Media. Concretamente, se analizan las fórmulas propias del lenguaje técnico jurídico y los cultismos contenidos en instrumentos notariales escritos o gestionados en Calahorra en el siglo XIII.

La rigidez que caracteriza a estos documentos se manifiesta principalmente en el uso recurrente de fórmulas estereotipadas. Por otro lado, los abundantes cultismos entresacados del corpus estudiado muestran que las escrituras fueron un importante vehículo de penetración de los mismos. La necesidad de denominar conceptos técnicos motivó que se adaptasen palabras calcadas de cartas y formularios latinos.

RÉSUMÉ: Dans l'article suivant on présente une étude linguistique des traits qui caractérisent la prose notariale du Moyen Âge. D'une manière plus concrète, on analyse les formules techniques propres au langage juridique et les mots savants contenus dans des actes notariaux écrits et gardés à Calahorra pendant le XIII ${ }^{e}$ siècle.

La rigidité qui caractérise ces documents se manifeste surtout dans l'utilisation fréquente de formules stéréotypées. D'ailleurs, l'abondance de mots savants tirés du corpus étudié montre qu'ils ont trouvé un important moyen de pénétration dans ces écrits. Le besoin de désigner des concepts techniques a donné lieu à l'adaptation de mots calqués de lettres et formulaires latins.
\end{abstract}

\section{Cuestiones previas}

Las escrituras notariales romances constituyen un interesante punto de partida para estudiar la penetración y el afianzamiento de los cultismos -principalmente jurídicos-, así como de fórmulas propias de este lenguaje de escribanía. La prosa jurídica de estos documentos arrastra una notable técnica de escuela, arcaizante muchas veces, y determina que aparezcan con relativa frecuencia cultismos engastados en fórmulas

* Doctora en Filología Hispánica por la Universidad de La Rioja. Profesora de Lengua Española e Investigadora Agregada del Instituto de Estudios Riojanos. I.E.S. "Esteban Manuel de Villegas", Ctra. de Huércanos, s/n, 26300 - Nájera (La Rioja). 
estereotipadas propias de la lengua notarial. El análisis de estos aspectos resulta de gran interés para el estudioso del ámbito filológico.

Teniendo en cuenta, pues, la riqueza de testimonios lingüísticos que se recogen en estos instrumentos, ofrezco en el presente artículo el análisis de ciertas fórmulas propias del lenguaje técnico jurídico y de algunos cultismos -también pertenecientes a la esfera jurídica- contenidos en documentos notariales escritos o gestionados en Calahorra durante el siglo XIII; si bien antes y a modo de introducción, presento una breve caracterización del estado lingüístico de los mismos.

Para llevar a cabo el estudio propuesto, he partido de un corpus proporcionado por la Colección Diplomática Medieval de La Rioja. Tomo IV - Documentos siglo $X I I I^{1}$. En primer lugar, he seleccionado las cartas romances escritas o gestionadas en Calahorra. En segundo lugar, he elegido aquellas que reflejan directamente los hechos jurídicos y administrativos que atañen a la vida conventual o a la de los feligreses de la zona en el desarrollo de sus transacciones comerciales. En total, he estudiado 100 escrituras, la mayoría de ellas conservadas en el Archivo Catedralicio de Calahorra. Es documentación de carácter privado que se desglosa de la siguiente manera: 68 escrituras de compraventa, 13 donaciones, 10 permutas y 19 arrendamientos.

A pesar de la cantidad de documentos diplomáticos utilizados en el presente estudio, dejo constancia de que no es objeto de mi trabajo exponer el contenido diplomático o estructura textual de los mismos -otros estudios ${ }^{2}$ se han dedicado a ello-, si bien haré alusiones, claro está, a ciertos elementos que intervienen en la organización del discurso diplomático.

\section{Estado lingüístico de los documentos}

La lengua romance, como sabemos, se empieza a utilizar en los documentos con cierta regularidad a finales del XII y primeros años del siglo XIII, bien con palabras en

1. RODRÍGUEZ R. DE LAMA, Ildefonso: Colección Diplomática Medieval de La Rioja. Tomo IV Documentos siglo XIII. Logroño, IER, 1989.

2. Cito, a modo de ejemplo, algunos de los mismos:

DÍEZ DE REVENGA TORRES, Pilar: "Estructura textual de unas cartas medievales". Homenaje al profesor Rafael Lapesa, Universidad de Murcia, 1990, págs. 109-119.

FLORIANO CUMBREÑO, Antonio C.: Curso General de Paleografía y Diplomática Españolas. Oviedo, Imprenta La Cruz, 1946.

GARCÍA TURZA, Francisco Javier: "Introducción a la diplomática monástica de San Millán de la Cogolla en el siglo XIII". Actas del IX Congreso de la Asociación de Archiveros de la Iglesia de España celebrado en Oviedo - Valdediós (13 al 16 de septiembre). Asociación de Archiveros de la Iglesia de España. Memoria Ecclesiae VI: Órdenes Monásticas y Archivos de la Iglesia (I). Santoral hispano-mozárabe en España. Oviedo, 1995, págs. 345-360.

SÁNCHEZ, Galo: "Colección de fórmulas jurídicas castellanas de la Edad Media”. AHDE, 2, 1925, págs. $470-491$. 
romance intercaladas en un documento redactado en latín medieval ${ }^{3}$ o bien en documentos escritos totalmente en romance. No obstante, se conservan algunos del siglo $\mathrm{XI}$ tan intensamente romanceados que pueden considerarse como antiguos monumentos de las lenguas románicas peninsulares: es el caso del "fuero de las defesas de Matrice" (San Millán de la Cogolla, 1044).

Las cartas están escritas principalmente en romance, si bien asoma esporádicamente alguna fórmula o voz latinas. La lengua usada en estos documentos presenta, pues, diferentes registros lingüísticos. Así observamos que ya en algunos instrumentos se va filtrando un lenguaje más coloquial, muy adulterado por dialectalismos.

Uno de los rasgos más destacados del español primitivo, como ya estudió Lapesa $^{4}$, es la diversidad de soluciones que ofrece. Los fenómenos que apunta el autor también se aprecian en los instrumentos notariales expurgados; algunos de ellos se aprecian, sobre todo, en las voces que ofrecen variabilidad grafemática.

El estudio del español arcaico demuestra que la variabilidad lingüística de este período se debe en gran parte a la enorme presión que sobre ella ejercía el latín -muchas veces es precisamente la forma más culta la que finalmente prevalece-. Las oscilaciones que se observan son propias del estado de inseguridad en que se encuentra la lengua. En medio de la coexistencia de normas la evolución lingüística avanza con pasos lentos, pero firmes.

\section{Análisis del lenguaje técnico jurídico}

\subsection{Secuencias formularias}

Habrá que convenir en que los documentos notariales proporcionan al investigador, como es lógico, abundantísimos testimonios ${ }^{5}$, independientemente de la valora-

3. No olvidemos que en esta época coexisten diferentes registros lingüísticos. Así tenemos textos latinos romanceados y textos romances latinizados. Estamos, pues, ante dos entidades lingüísticas bien diferenciadas. El romance tiene un extraordinario rendimiento. Para Bastardas y Parera (BASTARDAS Y PARERA, Juan: "El latín de la Península Ibérica: el latín medieval”. Enciclopedia Lingüística Hispánica, dirigida por M. Alvar, A. Badía, R. de Balbín y F. L. Contreras. Madrid, CSIC, 1960, Vol.I, págs. 251290), el "latín vulgar" o "El latín medieval es, pues, el latín escrito, y, en determinadas ocasiones, incluso hablado, a partir del momento en que la lengua usual y cotidiana, la lengua materna, en el sentido más estricto de la palabra, en la conciencia lingüística del sujeto hablante, no es ya latín, sino una lengua distinta. [...] El latín medieval es una lengua aprendida, y precisamente la conciencia de que se escribe una lengua absolutamente aprendida y sin sujetos hablantes espontáneos es lo que caracteriza el latín medieval" (pág. 251).

4. Lapesa destaca como generales, y entre otros, los siguientes fenómenos: la inseguridad respecto de las vocales pretónica y postónica; la alternancia de conservación y pérdida de $e$ final; la vacilación fomentaba ultracorrecciones o la lucha de las consonantes sordas intervocálicas con las sonoras (LAPESA, Rafael: Historia de la lengua española. Madrid, Gredos, 1981, 9. ${ }^{a}$ ed., págs. 163-165).

5. En este sentido, resultan interesantes los trabajos de KIVIHARJU, Jukka: "La importancia de los documentos notariales latinos de los siglos XII y XIII para el conocimiento del léxico romance". Actas del 
ción que de ellos se haga como fuente para el análisis de la lengua hablada en el área donde son o fueron redactados.

El carácter formulario ${ }^{6}$ de las escrituras ofrece más datos favorables que perjudiciales para el estudioso: el conjunto mayor de tecnicismos jurídicos ha sido entresacado de las secuencias formularias; además, es en ellas donde mejor se advierten las acepciones específicas de las voces comunes. Las estructuras reiteradas propias de esta prosa notarial que he hallado en los documentos expurgados son las que cito a continuación.

Las fórmulas estereotipadas de espontaneidad estar en mi seso y en mi memoria, así como ser en mi seso y en mi memoria, se consignan en el protocolo inicial de los documentos para dar fiabilidad al acto contractual (Conoscida cosa sea a quantos esta carta uidieren que yo don P[edro] prior [...] estando en mi seso y en mi memoria [...] do en remision de mis pecados [...]: 1246, 162). Como indica Cantera Montenegro ${ }^{7}$, son "frases que si reflejan cierto formulismo en su redacción no pueden ocultar la imprescindible consciencia del testador para que este acto tuviese valor" (págs. 37-38).

$\mathrm{El}$ adjetivo bueno forma parte de sintagmas casi formularios que califican la actitud de los otorgantes ante el negocio jurídico que realizan: bona memoria, bon corazon y bona uolumptad ([...] yo don Gonzaluo de Burgos [...] en bona memoria et de bon corazon, et de bona uolumptad, dono a vos [...] todo aquello heredamiento [...]: 1259, 243).

Dentro de las expresiones circunstanciales de solemnidad que legalizan el acto, el protocolo inicial recoge la dirección de los destinatarios en fórmulas como la siguiente y otras semejantes: a los presentes y a los que son por venir (Connuscuda cosa sea a quantos omnes esta carta uieren e oyeren, tan bien a los presentes como a los que son por venir, como nos don Martin Lopez, por la gracia de Dios abbat [...]

II Congreso Internacional de Historia de la Lengua. Editadas por M. ARIZA, R. CANO, J. M. ${ }^{\text {a MENDO- }}$ ZA y A. NARBONA. Madrid, Pabellón de España, 1992, Vol. I, págs. 981-991; y de LAGÜÉNS GRACIA, Vicente: Léxico jurídico en documentos notariales aragoneses de la Edad Media (siglos XIV y XV). Zaragoza, Gobierno de Aragón - Departamento de Cultura y Educación, 1992.

6. Frago Gracia (FRAGO GRACIA, Juan A.: "Sociolingüística de la fórmula notarial". LEA, VII, 1985, págs. 191-201 ) analiza el carácter de inmovilismo propio del lenguaje jurídico: “[...] el Medievo europeo [...] vivió bajo una tupida red de interdependencias sociales y de normas de conducta, cuya legislación obedecía en el aspecto linguiístico a la utilización de un acervo de secuencias preestablecidas; a ellas se recurría para la redacción de sentencias, contratos de toda clase (compraventa, donación, cartas de hermandad o de ahijamiento), compromisos de vasallaje, disposiciones testamentarias, etcétera. El lenguaje jurídico implica, pues, la afirmación supraindividual del estilo, que ha de ser uniforme, o casi, en cualquier documento de idéntica caracterización legal que se refiera a una misma comunidad. Consecuencia directa de este hecho es el acusado inmovilismo, en las formas lingüísticas -palabras o giros sintácticos-, de modo que el arcaísmo encuentra fácil acogida en este medio abundante de prescripciones codificadas [...]” (pág. 193).

7. CANTERA MONTENEGRO, Margarita: "Derecho y sociedad en la Rioja bajomedieval a través de los testamentos (siglos XIII-XV)”. Hispania, XLVII, 165, 1987, págs. 33-82. 
viemos priuilegios de los abbades nuestros antecessores en que fizieron muchas donaciones [...]: 1287, 422).

Son usuales los sintagmas formados por los adjetivos antedicho, auandicho, deuandito, dicho y sobredicho antepuestos al nombre de las personas que intervienen en el acto, como otorgantes, testigos, etc. (E por questa cosa sea mas firme el dean e el cabillo sobredichos con otorgamiento de don Gonçaluo Yuannes antedichos [...]: 1255, 222) o al de una demarcación territorial nombrada en el documento ([...] et porque somos bien pagados del auandicho cambio... [...] de lauandicha pieza [...]: 1262, 256).

La frase estereotipada de carácter formulario por toda uida se utiliza en los documentos para expresar la larga duración de los contratos ([...] arrendo d'uos [...] aquella uuestra heredad que auedes en Tannen con so cassa por toda mi uida [...]: 1253, 207).

A la necesidad de rigor expositivo para reforzar los términos de cada compromiso responderían las imprecaciones que van dirigidas al posible infractor de alguna de sus cláusulas, uso que, por cierto, hunde sus raíces en el Derecho Romano ${ }^{8}$ pero del que se verifican equivalencias en culturas ajenas al ámbito europeo. Observamos en las cartas la siguiente fórmula conminatoria: El crebantador destas cartas peche al rey [...] solidos, e doble las heredades a cada uno a sos lindes [...] (1260, 250), esto es, que quien incumpla el contrato deberá ser castigado pagando una cantidad de dinero al rey e incrementando doblemente "en sus límites" los terrenos fruto de la transacción.

Al final del cuerpo de estos instrumentos notariales se consigna el patrón lingüístico testigos fueron presentes e rogados (Testigos fueron presentes e rogados que mandaron escriuir sus nombres en esta carta [...]: 1267, 285).

En el protocolo final de los documentos de compraventa, concretamente tras la data, figura la siguiente fórmula de confirmación ${ }^{9}$ : Et porque sea mas firme e non uenga en dubda feymos dos cartas [...] (1266, 283).

Se registran en abundantes documentos construcciones formularias con las que se manifiesta la data tópica y cronológica, a menudo insertas en el signum notarial; así: Esto fue feyto; y a continuación el día, mes y era: dias andados o dias por andar, junto con el mes correspondiente y la era (Esto fue fecho en pleno Cabillo, seyendo presentes maestre Johan [...]. Viernes, tres dias andados de Jenero. Era M. ${ }^{a}$ CCC. ${ }^{a}$ [...]: 1276, 349).

El sintagma en testimonio fiç en ellas este mi signo acostumbrado (1284, 410), repetido generalmente en el escatocolo, corresponde a la fórmula que, indicada expresamente por el escriba, testimonia la autenticidad de la carta.

8. FRAGO GRACIA, J. A.: "Sociolingüística...”, pág. 195.

9. Remito a tres interesantes artículos que abordan el estudio de la confirmación en privilegios:

PARDO RODRÍGUEZ, M. a Luisa: "La confirmación en los documentos señoriales de la Baja Edad Media. Aportación a su estudio”. Historia. Instituciones. Documentos, 12, 1985, págs. 247-275.

- "La diplomática señorial en la corona de Castilla". AEM, 22, 1992, págs. 233-246.

SANZ FUENTES, M. 'Josefa: "La confirmación de privilegios en la Baja Edad Media. Aportación a su estudio". Historia. Instituciones. Documentos, 6, 1979, págs. 341-367. 
La recurrencia a dichas estructuras suministra al lenguaje notarial un rígido armazón que se completa con los datos concretos propios de cada escritura, contribuyendo de ese modo a la expresión de ideas bastante precisas con una gran economía de medios. La repetición de distintas expresiones fijas en los documentos se justifica, además, por otros diversos motivos. Así, si lo que se pretende es dejar absolutamente claro que una propiedad se transmite íntegra, nada mejor para ello que intercalar algún elemento de corroboración como el sintagma del fundamento de la tierra fasta las nuues del cielo $(1251,198)$ y que se inscribe en la parte introductoria del documento para dejar clara constancia de que el objeto de la transacción (propiedad y, se entiende, derechos que ella conlleva) se ofrece íntegro.

Por otra parte, la configuración repetitiva propia del lenguaje jurídico también se manifiesta en la coordinación de sinónimos -aspecto estudiado, entre otros, por Saralegui y Pérez-Salazar ${ }^{10}$, Codoñer ${ }^{11}$ y Lagüéns ${ }^{12}$-, fenómeno que es constante en Berceo (Giménez Resano ${ }^{13}$ y Sala ${ }^{14}$ ). El estilo de los textos jurídicos se caracteriza por su conservadurismo y por su afán de exactitud. No es de extrañar, pues, que se consignen estas reiteraciones léxicas que responden a un rasgo estilístico frecuente en este lenguaje y que consiste, como ya he señalado, en acumular vocablos de igual significado ${ }^{15}$. Algunas de las parejas sinonímicas que se encuentran en los documentos son: amor e concordia (1285, 423), bien e complidamente (1277, 359), contienda e uaraia (1237, 119), costas e missiones (1266, 283), firme e valedero (1269, 299), firme e estable (1274, 332), firme e non venga en dubda (1271, 316), o saluo e quito $(1284,411)$.

Dentro también de este apartado dedicado al estudio de las expresiones formularias, es obligado mencionar la utilización de pleonasmos, como por ejemplo el que constituye la locución adverbial por(a) siempre iamas, que se atestigua en varios

10. SARALEGUI, Carmen y PÉREZ-SALAZAR, Carmela: “Coordinación de sinónimos en textos jurídicos". Rilce, 8, 1992, págs. 112-133.

11. CODOÑER, Carmen: "Léxico de las fórmulas de donación en documentos del siglo X". Emérita, XL, fasc. 1. ${ }^{\circ}, 1972$, págs. 141-149.

12. LAGÜÉNS GRACIA, Vicente: "Semántica jurídica: binomios léxicos en la prosa notarial”. Actas del II Congreso Internacional de Historia de la Lengua. Editadas por M. ARIZA, R. CANO, J. M. ${ }^{\mathrm{a}}$ MENDOZA y A. NARBONA. Madrid, Pabellón de España, 1992. Vol. I, págs. 1121-1128.

13. GIMÉNEZ RESANO, Gaudioso: El mester poético de Gonzalo de Berceo. Logroño, Servicio de Cultura de la Excma. Diputación Provincial - Instituto de Estudios Riojanos, 1976, págs. 52-58.

14. SALA, Rafael: La lengua y el estilo de Gonzalo de Berceo. Logroño, Instituto de Estudios Riojanos, 1983 (en el capítulo Sinonimia y repetición, págs. 131-138).

15. Para Lagüéns, "el frecuente empleo de voces coordinadas formando binomios léxicos de acumulación semántica, con los que parece pretenderse [...] la transparencia significativa, la precisión conceptual [no siempre se consigue]. En multitud de ocasiones, he intentado determinar si dichas voces eran o no idénticas en cuanto a su contenido: bastará recordar ejemplo como asenso, consenso y expreso consentimiento, autoridad y decreto, avenencia y composición, firmeza y seguridad [...], notorio y manifiesto [...]. Si acabo de señalar la relación del uso y abuso de este recurso notarial [...], es porque, en ocasiones, uno de los términos coordinados es un vocablo polisémico de la lengua común y el otro (u otros) un tecnicismo jurídico más especializado semánticamente” (Léxico jurídico en documentos notariales aragoneses..., pág. 283). 
documentos (En tal manera que ayan la dicha eglesia libre e quita para siempre iamas con estos heredamientos [...]: 1285, 423).

Por otro lado, no se pueden ignorar ciertas fórmulas usuales en las cartas que, si bien no pertenecen al lenguaje jurídico, tienen igual rendimiento. Me refiero a las frases estereotipadas propias del mundo eclesiástico, ámbito que influyó de forma tan especial en el mundo medieval. En concreto, registro las siguientes.

Una de las cláusulas que se recogen en la sanctio o parte del cuerpo donde se expresan las fórmulas ${ }^{16}$ que tienen por objeto garantizar el cumplimiento de la acción jurídica contenida en la parte dispositiva es Aya la ira de Dios, que equivale a la sanción -figurada, claro está- que sufren los incumplidores del contrato (Crebantador de esta nuestra abinentia e nuestro paramiento aya la ira de Dios todopode[roso] e pecte al rey quinientos morauedis en coto [...]: 1237, 119).

La frase estereotipada iurar sobre sanctos euangelios se enmarca dentro de la tradición de los juramentos que proferían los cristianos quienes, según Yanguas ${ }^{17}$, creían que la gravedad de sus perjurios estaba en razón de la mayor o menor santidad del objeto a quien ponían por testigo en ellos ([...] don Pedro Prior, e Juan Meder [...] juramos sobre santos euangelios, que nos nin nuestros fijos [...] que nunca lo demandaremos nin nunca contra el vayamos [...]: 1294, 507).

La frase casi formularia en remision de mis pecados conserva el sentido bíblico de 'en perdón de los pecados' ([...] do en remision de mis pecados [...] al dean y al cabillo dessi mismo logar, VI. morabetinos de encens que e en Logrono en el forno de la Puerta de Mercado [...]: 1246, 162).

Concluyo este apartado destacando una vez más el rasgo de uniformidad que caracteriza al lenguaje jurídico; de aquí deriva su estilo repetitivo que se manifiesta en el típico formulismo ya señalado. Consecuencia directa de este hecho es el acusado inmovilismo en las formas lingüísticas -palabras o giros sintácticos-, "de forma que el arcaísmo encuentra fácil acogida en este medio abundante de prescripciones codificadas"18.

\subsection{Cultismos}

El abundante número de voces cultas que se recoge en los documentos seleccionados pertenece, principalmente, a las esferas jurídica y eclesiástica, importantes arsenales de voces latinas - como ya indicaron, entre otros, Alvar y Mariner ${ }^{19}$.

16. DÍEZ DE REVENGA TORRES, Pilar: "Algunas expresiones de la sanctio en cartas medievales". Voces, 2, 1991, págs. 63-72.

17. Cfr. Yanguas (YANGUAS Y MIRANDA, José: Diccionario de antigüedades del Reino de Navarra. Pamplona, Institución Príncipe de Viana, 1964 (reimpr. de 1840). 3 vols.), s.v. juramentos.

18. FRAGO GRACIA, J. A.: “Sociolingüística...”, pág. 193.

19. Alvar y Mariner consideran, en este interesante artículo (ALVAR, Manuel y MARINER, Sebastián: "Latinismos". Enciclopedia Lingüística Hispánica, dirigida por M. Alvar, A. Badía, R. de 
Las escrituras notariales romances fueron vehículo constante de penetración y afianzamiento de cultismos y semicultismos. Sabido es que la necesidad de expresión nocional de numerosos conceptos técnicos fue satisfecha por los escribanos mediante la adaptación de palabras calcadas de cartas y formularios latinos. Y a este respecto, las notas que Bustos Tovar elaboró en relación con los textos jurídicos y notariales del siglo XIII resultan fundamentales para conocer el intéres que alcanzan los cultismos en la prosa jurídica ${ }^{20}$.

Ofrecen interés los cultismos para observar hasta dónde ha llegado el grado de adaptación formal y las vacilaciones que las épocas de evolución idiomática producen. Hay escasa variedad en los campos de significación, pero gran vacilación formal. En ellos se ve la tensión entre el latín y el romance y la naturaleza de sus relaciones en épocas preliterarias.

Enumero a continuación, a modo de muestra significativa -la lista es interminable-, algunas de las voces cultas pertenecientes al ámbito jurídico -parcelación coherente con el tema tratado, si bien en algunos casos resulta difícil su inclusión en el campo léxico estudiado- que se presentan en los documentos con forma idéntica o similar a la del español actual, salvadas, por supuesto, las diferencias fonológicas diacrónicas: abenentia, affirmar, auctoridat, carta, çitar, composicion, confirmar, consentimiento, corrupcion, deçima, defender, demanda, demandar, donacion, escribano, escripto, excusacion, falsedat, firmar, firme, iura, iurado, iurar, iurisdiccion, juramiento, libre, mandado, mandamiento, manifiesto, memoria, natural, neccesario, notario, obligar, obligation, orden, ordenar, otorgamiento, otorgar, perdonar, pertenenencia, plazenteria, plazer, plazo, pleneramiente, posesion, quitar, quito, remembrança, remision, remiso, renunçiar, scriptor, sentençiar, signo, succesor, sustentamiento, tabellion, temporal, testamento, teste, testimonio, tractado, translacion, translado y uoluntad.

Es importante considerar que en algunas de estas voces ha intervenido el excesivo cuidado del amanuense, que es la causa de la aparición de no pocas ultracorrecciones. Basten como ejemplo los términos que a continuación muestro con grafías cultas o latinizantes: auctoridat, corrupcion, escripto, excusacion, scriptor, tabellion, tractado, translacion, translado y uolumptad.

Aparte de estos hipercultismos gráficos, es interesante subrayar que en ocasiones se registran dobletes o tripletes formales para una misma voz: resultados cultos y populares -desde planteamientos fonéticos-, descendientes de un único étimo latino,

Balbín y F. L. Contreras. Madrid, CSIC, 1967, Vol. II, págs. 3-49), que "el latinismo es constante a lo largo de toda nuestra historia lingüística y, además, afecta tanto a la expresión de temas religiosos [...] como a las traducciones bíblicas [...]; a la lengua teórica de un jurista (Rey Sabio) como a los Fueros de los siglos XIII o XIV [...]” (pág. 48).

20. BUSTOS TOVAR, José Jesús de: Contribución al estudio del cultismo léxico medieval. Madrid, Anejo XXVIII del BRAE, 1974, págs. 159-190. 
pueden convivir en la misma documentación. Sirvan de muestra los casos siguientes: junto a abinentia (abinencia) se anota abenencia (abenentia); el culto deçima alterna con diezmo; convive pertinencia con el culto pertenencia. La diversidad formal puede obedecer a causas etimológicas (actoridat frente a auctoridat, autoridat) o a determinados comportamientos fonéticos evolutivos que las voces cultas pueden compartir con las populares; así, inestabilidad en el timbre de las vocales átonas: abinentia-abenencia, pertinencia-pertenencia; o incluso la presencia de dispares variantes que alternan en los documentos.

Estos ejemplos entresacados de la documentación riojana ilustran la contienda formal que, según Bustos, presentan estas voces o similares y que es consecuencia de una coincidencia cronológica de normas diferentes, cuales son el romanceamiento y la relatinización. Afirma este autor que "la prosa jurídica y administrativa refleja una realidad inmediata para el hombre medieval, y por tanto, su léxico, enquistado en un expresión técnica de raíz latinizante, va perdiendo su aspecto de clisé arcaizante. Se integra así de forma gradual en la lengua de uso general. El frecuente empleo de cultismos nos muestra la seguridad con que se los asimila"21.

\section{Conclusiones}

El análisis de los documentos medievales riojanos me ha permitido, en primer lugar, esbozar el estado en el que se encuentra la lengua de estas cartas -responde éste a un romance con los rasgos propios de inestabilidad lingüística del español primitivo-, y, en segundo lugar, mostrar algunos de los aspectos que caracterizan la prosa notarial desde el punto de vista lingüístico.

El lenguaje técnico jurídico reflejado en estas escrituras no sólo se aprecia en el léxico, sino también en la reiterada utilización de las fórmulas notariales configuradas como esquemas fijos. La recurrencia a estas fórmulas estereotipadas suministra un rígido armazón que determina los usos lingüísticos de estos instrumentos. Es más, las escrituras romances fueron un medio de penetración y consolidación de abundantes cultismos, ya que la necesidad de expresar determinados conceptos técnicos se vio satisfecha por parte de los escribanos adaptando palabras calcadas de cartas y formularios latinos.

Finalmente, destaco la utilidad que ofrece la colección diplomática expurgada para el estudio de diferentes aspectos relacionados con el romance medieval de La Rioja, pero no sólo para el filólogo, sino también para el investigador de cualquier otra disciplina humanística.

21. BUSTOS TOVAR, J. J.: Contribución al estudio del cultismo..., págs. 294-295. 